\title{
PEEP or no PEEP: That is not the question
}

\author{
JESÚS VILLAR MD PhD FCCM, ARTHUR S SLUTSKY MD \\ Research Institute, Hospital de la Candelaria, Tenerife, Canary Islands, Spain; \\ and Samuel Lunenfeld Research Institute, Mount Sinai Hospital, Respiratory Division, \\ Department of Medicine, University of Toronto, Toronto, Ontario
}

J Villar, AS SLUTSKy. PEEP or no PEEP: That is not the question. Can Respir J 1996;3(6):361-367.

Generally, positive end-expiratory pressure (PEEP) is applied to improve oxygenation, and has been shown to improve gas exchange and lung compliance in acute lung injury, but it is not without risk. To date, no controlled outcome studies have been published to demonstrate the best method of choosing the level of PEEP. Furthermore, it is not known whether the application of PEEP contributes to lung damage or helps to ameliorate it. The authors review the goals of PEEP and the current evidence on its effects on lung injury and its clinical utility. In the absence of controlled clinical trials, the use of PEEP in acute respiratory distress syndrome needs to be guided by physiological principles that balance the beneficial effects of an increase in functional residual capacity, prevention of alveolar closure, redistribution of lung water and improved ventilation of low ventilation-perfusion areas against the potential harm of alveolar rupture (barotrauma and 'volutrauma') and reduction in cardiac output.

\section{Avec ou sans PEEP : Ce n'est pas la question}

RÉSUMÉ : Habituellement on applique une pression télé-expiratoire positive (PEEP) pour améliorer l'oxygénation, et il a été démontré que cette manoeuvre améliore les échanges gazeux et la compliance pulmonaire dans les cas de traumatisme pulmonaire aigu, mais qu'elle comporte certains risques. Actuellement, aucune étude comparative des résultats n'a été publiée pour démontrer quelle est la meilleure méthode pour choisir un niveau de PEEP. De plus, on ne sait pas si l'application d'une PEEP contribue à endommager les poumons ou au contraire à améliorer l'état pulmonaire. Les auteurs passent en revue les objectifs de la PEEP et les données courantes sur ses effets sur l'atteinte pulmonaire et sur son utilité clinique. En l'absence d'essais cliniques comparatifs, l'utilisation de la PEEP dans le syndrome de détresse respiratoire aiguë a besoin d'être guidée par des principes physiologiques qui font que les effets bénéfiques d'une augmentation de la capacité résiduelle fonctionnelle, de la prévention de la fermeture alvéolaire, de la redistribution de l'eau dans le poumon et de l'amélioration de la ventilation des zones de faible ventilation-perfusion s'équilibrent par rapport au risque potentiel de rupture alvéolaire (barotraumatisme et «volumotraumatisme») et à celui d'une diminution du débit cardiaque.

Key Words: Positive end-expiratory pressure

$\mathrm{P}$ ositive end-expiratory pressure (PEEP) has become an essential component of the care of many critically ill patients who require ventilatory support. With the application of PEEP, the baseline end-expiratory pressure in mechanically ventilated patients is elevated above atmospheric pressure. The use of PEEP was first reported by Barach et al (1) in 1938, and it has been used widely since Ashbaugh et al (2), in their classic description of the acute respiratory distress syndrome (ARDS), reported that PEEP improved oxygenation and allowed ventilation with gas of lower inspired oxygen concentration. It is well established that PEEP, compared with ventilation using atmospheric end-expiratory pressure, increases functional residual capacity (FRC), probably by preventing airway closure and recruiting previously unventilated alveoli (3). The increase in FRC may also increase lung compliance. However, although there is no question that

Correspondence: Dr Jesús Villar, Director, Research Institute, Hospital de la Candelaria, Santa Cruz, de Tenerife, Canary Islands, Spain. Telephone 34-22-602389, fax34-22-600562,e-mail jvillar@arrakis.es 


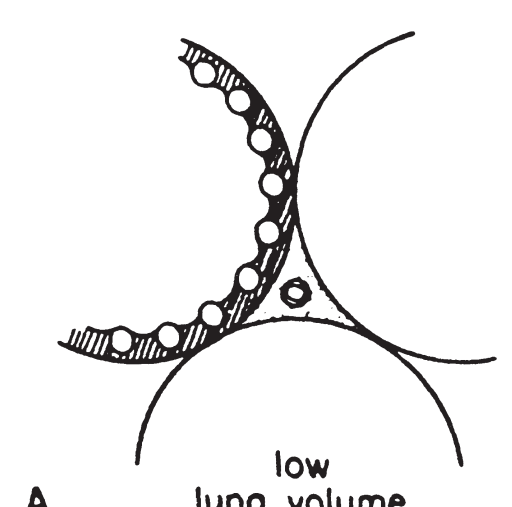

A

lung volume

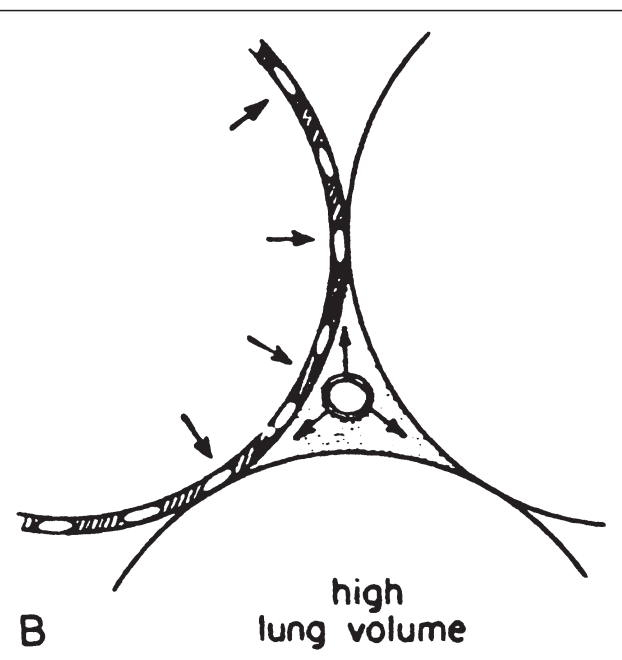

Figure 1) As a result of peak end-expiratory pressure (PEEP) increasing lung volume (B), alveolar capillaries are stretched and compressed. Extra-alveolar and corner vessels between alveoli are expanded, which increases the flux of fluid into the interstitial space. Without PEEP (A) these changes are reversed. Reproduced with permission from reference 8

PEEP can improve oxygenation in selected patients, its beneficial effects on morbidity and mortality have not been conclusively demonstrated. It is not known whether the application of PEEP contributes to lung damage or helps to ameliorate it.

\section{GOALS OF PEEP: BASIC MECHANISMS AND PULMONARY EFFECTS}

PEEP is applied generally to improve oxygenation. Improvement in oxygenation is usually not observed unless there is a concomitant increase in FRC. Three mechanisms have been proposed to explain the improved pulmonary function and gas exchange with PEEP (4): first, increased FRC; second, alveolar recruitment; and third, redistribution of extravascular lung water. All of these mechanisms can lead to improved ventilation-perfusion matching.

Increased FRC and alveolar recruitment: Regardless of the status of the pulmonary system, FRC increases with the application of PEEP as the result of three separate effects $(4,5)$. First, PEEP increases lung volume as a result of distension of already patent airways and alveoli by a degree that is dependent on system compliance. Therefore, the stiffer the system, the smaller the volume change. Second, application of PEEP prevents alveolar collapse during expiration. Dependent small airways tend to collapse at low lung volumes. An improvement in oxygenation after the application of 5 to $10 \mathrm{~cm} \mathrm{H} \mathrm{H}_{2} \mathrm{O}$ in patients under general anesthesia is attributed to changes in the FRC-closing volume relationship (6). Third, PEEP above $10 \mathrm{~cm} \mathrm{H}{ }_{2} \mathrm{O}$ can recruit collapsed alveoli in acute lung injury. Alveolar recruitment describes reinflation of previously collapsed alveoli. During acute lung injury, PEEP can markedly alter the compliance of the lung by alveolar recruitment (7). The greater the alveolar collapse and pulmonary edema, the more the compliance curve shifts downward and to the right. As PEEP is applied and alveoli recruited, the pressure-volume curve shifts upwards and to the left. However, the application of excessive levels of PEEP can overdistend alveoli, moving alveolar volume to the flat portion of the pressure-volume curve and causing compliance to decrease $(7,8)$.

Redistribution of extravascular lung water: The effects of PEEP on extravascular lung water are complex and depend on the vascular surface area perfused and the relations among alveolar, arterial, interstitial and venous pressures. Studies in animals looking at the effects of PEEP on extravascular lung water in both cardiogenic and noncardiogenic pulmonary edema have shown that the application of 5 to $20 \mathrm{~cm} \mathrm{H}_{2} \mathrm{O}$ is able to recruit flooded alveoli and improve oxygenation without diminishing lung water content (9). In general, by increasing intra-alveolar pressure, PEEP moves fluid from the interstitial space of alveolar vessels to the interstitial space around extra-alveolar vessels, thereby reducing the distance for oxygen diffusion $(8,9)$ (Figure 1).

Ventilation-perfusion relationships: In certain patients with ARDS, PEEP produces marked improvement in gas exchange. However, in other patients, PEEP produces equivocal and even detrimental changes, often combined with reductions in cardiac output. In normal lungs, the lowest ventilation/perfusion ratio $(\dot{V} / \dot{Q})$ is found in the gravitydependent areas. In acute lung injury, low levels of PEEP (5 to $10 \mathrm{~cm} \mathrm{H}_{2} \mathrm{O}$ ) reduce shunt and abolish low $\dot{\mathrm{V}} / \dot{\mathrm{Q}}$ regions at the expense of creating areas of dead space ventilation (very high $\dot{V} / \dot{Q})$. Dueck et al (10) assessed the effects of four levels of PEEP $\left(5,10,15\right.$ and $\left.20 \mathrm{~cm} \mathrm{H}_{2} \mathrm{O}\right)$ on the distributions of $\dot{V} / \dot{Q}$ in normal and oleic acid-induced edematous lungs in dogs. They reported that, in animals with severe pulmonary edema, regions of intrapulmonary shunt were eliminated by PEEP, but dead space emerged only with higher levels of PEEP.

In humans studies, Dantzker et al (11) found that the application of PEEP is accompanied by decreased bloodflow to poorly ventilated regions. In addition, PEEP abolished 
regions of shunt and redistributed bloodflow from regions with high shunt to regions of very low $\dot{\mathrm{V}} / \dot{\mathrm{Q}}$. Thus, PEEP decreased the number of shunt units while increasing the number of adequately ventilated and perfused units. Manzano et al (12) were able to decrease shunt and increase oxygenation when cardiac output was not decreased during the application of PEEP. After administration of fluids and dopamine to patients on high levels of PEEP (10 to $30 \mathrm{~cm} \mathrm{H}_{2} \mathrm{O}$ ), Manzano et al found that oxygen transport increased and shunt decreased with a preserved cardiac output. This finding supports the hypothesis that the reduction of shunt may be independent of decreased cardiac output induced by PEEP.

\section{CARDIOVASCULAR EFFECTS OF PEEP}

Along with the increase in FRC, PEEP increases pleural pressure. This increase produces a reduction of systemic venous return, and a decrease of the end-diastolic volume and stroke volume of both ventricles, causing a decrease in cardiac output. Qvist et al (13) demonstrated in anesthetized, paralyzed dogs that increases in pleural pressure with PEEP were associated with diminished transmural right atrial pressures, representing decreased right atrial filling pressure. They demonstrated that increasing intravascular volume by fluid administration could augment ventricular filling and reestablish a normal cardiac output despite the PEEP level, a finding confirmed in patients (12). An interesting mechanism to explain the decrease in cardiac output with PEEP was proposed by Fessler et al in 1993 (14). They hypothesized that when the lungs were inflated with PEEP they could also restrict venous return by directly compressing the thoracic vena cavae. They found that $10 \mathrm{~cm} \mathrm{H}_{2} \mathrm{O}$ of PEEP impedes venous return partly by direct compression of the inferior vena cavae, predominantly in positions in which the vena cava is nondependent. They speculated that this effect may be due to hyperinflation of lobes in the right lung.

Changes in pulmonary and systemic hemodynamics following the application of PEEP depend on PEEP level, pulmonary and thoracic compliance, vascular volume to vascular space relationships and myocardial contractility (8). Generally, it can be stated that in patients with normal lungs, about $50 \%$ of the applied PEEP is directly transmitted to the intrathoracic space; however, in patients with ARDS about $25 \%$ is transmitted (12). However, these estimates are very gross, and clinical judgement should guide decision-making.

\section{PEEP AND VENTILATOR-INDUCED LUNG INJURY}

There is no question that PEEP can improve oxygenation in selected patients; however, its beneficial effects on morbidity and mortality have not been conclusively demonstrated. The use of PEEP as a purely supportive therapy is not without risk. The benefits of PEEP may be counterbalanced by such complications as a reduction in cardiac output and the risk of further damage to the lungs.

Patients ventilated with positive pressures may be predisposed to pulmonary barotrauma. For barotrauma to occur, three factors must usually be present: lung disease, overdistension and pressure (15). Since ARDS is a nonhomogeneous

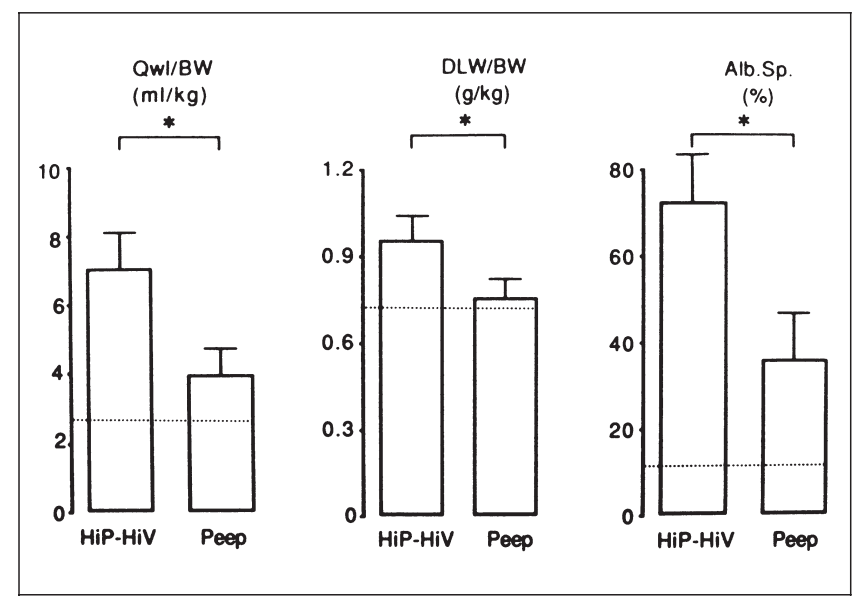

Figure 2) Effect of $10 \mathrm{~cm} \mathrm{H}_{2} \mathrm{O}$ peak end-expiratory pressure (PEEP) on high peak airway pressure-induced pulmonary edema. When PEEP is applied, all indexes of edema were diminished. $* P<0.001$. Alb. sp. Distribution of albumin; BW Body weight; DLW Dry lung weight; HiP High pressure; HiV High volume; Qwl Extravascular lung water. Reproduced with permission from reference 17

process, overdistension of a given lung unit may be achieved at any PEEP level. Therefore, the amount of overdistension achieved at a given level of PEEP determines the likehood of barotrauma. Pulmonary barotrauma is commonly used to refer to any disorder that produces extra-alveolar gas. Pneumothorax, pneumomediastinum and subcutaneous emphysema are the most common forms of barotrauma, and they are the result of spontaneous alveolar rupture. Increased end-expiratory pressure is usually not enough by itself to produce alveolar rupture. The prevalence of barotrauma ranges from $10 \%$ to $20 \%$ in most series, irrespective of whether PEEP is used.

Animal studies have shown that an increase in alveolar volume, and not just pressure, is the key element in producing disruption of alveolar walls $(16,17)$. On the other hand, there is evidence that PEEP may actually be protective. In the classic paper by Webb and Tierney (16), rats with normal lungs were mechanically ventilated for $1 \mathrm{~h}$. Those animals ventilated at pressures of $45 / 0 \mathrm{~cm} \mathrm{H}_{2} \mathrm{O}$ developed severe hypoxemia and decreased compliance, and died with extensive alveolar edema. Rats ventilated at $14 / 0 \mathrm{~cm} \mathrm{H}_{2} \mathrm{O}$ showed no abnormalities. The most interesting observation was that the application of $10 \mathrm{~cm} \mathrm{H}_{2} \mathrm{O}$ of PEEP, even when the same peak inspiratory pressure was used, dramatically reduced edema formation and no animals died. Dreyfuss et al (17) ventilated rats with normal lungs at $45 / 0 \mathrm{~cm} \mathrm{H}_{2} \mathrm{O}$ for $20 \mathrm{mins}$, after which there was widespread alveolar flooding and disruption of the alveolar epithelium. If high positive pressures were used but the volume expansion was limited by thoracoabdominal strapping, there was no protein leak. Similarly to Webb and Tierney, Dreyfuss et al (17) reported a marked reduction in both edema and protein leak when $10 \mathrm{~cm} \mathrm{H}_{2} \mathrm{O}$ of PEEP was applied.

Thus, our comprehension of the mechanism of high peak inspiratory pressure edema has evolved from the concept of barotrauma to that of 'volutrauma' (Figure 2). To date, no 


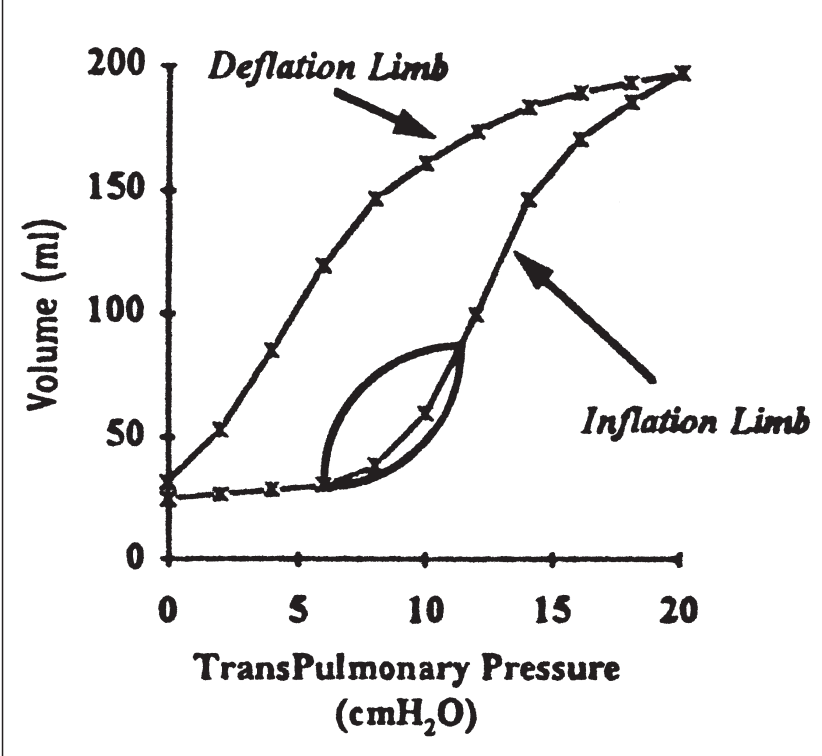

Figure 3) A typical pressure-volume curve in early acute respiratory distress syndrome

study has looked prospectively at the association of barotrauma with the use of PEEP. Lacking prospective, controlled studies in patients who developed alveolar rupture, clinicians have relied on anecdotal observations and retrospective reviews of available bedside data in the charts of patients identified through their x-rays reports as having any form of extra-alveolar gas (15). Although most of those observations have shown that patients who are treated with PEEP have a high incidence of alveolar rupture, they do not demonstrate that PEEP is the cause because patients who require the highest levels of PEEP are likely to be the sickest patients and thus are more prone to develop barotrauma.

\section{EFFECTS OF PEEP IN ACUTE LUNG INJURY}

PEEP has been shown to have significant effects on gas exchange and lung compliance during acute lung injury. In the initial phases of ARDS, the lungs are edematous and show a reduced compliance with an inflection point in the ascending limb of the pressure-volume curve. In late stages of ARDS, fibrosis develops, the lungs become stiff, compliance is very low and the pressure-volume curve does not show an inflection point. This inflection point represents the recruitment of collapsed alveoli and was first documented by Cook et al (18). In an oleic acid-induced pulmonary edema, Slutsky and colleagues (19) found that the inflection was explained on the basis of reopening of the units closed during deflation. Analysis of the pressure-volume curves in patients with acute lung injury allowed Matamis et al (20) to separate them into four groups: first, patients with normal compliance and no inflection point; second, patients with normal compliance and the presence of an inflection point; third, patients with reduced compliance and no inflection point; and fourth, patients with reduced compliance and the presence of an inflection point. This report was the first to assess the signifi- cance of the ascending limb of the pressure-volume curve in patients with acute lung injury. Normally, lung inflation occurs with modest increases in airway pressure. In the presence of pulmonary edema due to acute lung injury, tidal volume has access to fewer alveoli due to airspace flooding. The compression of the same tidal volume into fewer alveoli causes a large increase in the measured airway pressure. When a critical pressure is reached (inflection point), a sudden increment in volume occurs as alveoli are recruited and edema fluid is redistributed (Figure 3). As airway pressure falls to zero with deflation, alveolar closure and reflooding occur and a large peak pressure is again needed to reinflate the lung with the next breath.

Several studies performed by a group of investigators led by Gattinoni and Pesenti (21) in Milan provide evidence that the lung disease in patients with ARDS is heterogeneous, with collapsed and consolidated units mainly in the dependent regions and more healthy units in the nondependent regions. Using computerized tomography studies, Gattinoni and Pesenti (21) demonstrated that the healthy zone can represent as little as $20 \%$ of the normal lung volume; however, this 'baby' lung must accomplish the entire gas exchange during mechanical ventilation. Overinflation of the most compliant zones (which are less damaged) may occur because these zones receive the bulk of ventilation. When PEEP is applied to the acutely injured lung, a new recruitable zone can be detected as a reduction of the diseased zone is observed. Once this zone is fully recruited, it behaves as a relatively normal lung in terms of gas exchange and mechanics. Therefore, the main effect of augmenting PEEP is to maintain recruitment of alveolar units that were previously collapsed. Thus, since tidal volume is distributed to more alveoli, peak airway pressure is reduced and compliance is increased.

A number of animal studies have compared high PEEP with low PEEP strategies in acute lung injury (22-24). Corbridge et al (22), in an acid aspiration model, showed a lower shunt fraction and less pulmonary edema with high PEEP $\left(10 \mathrm{~cm} \mathrm{H}_{2} \mathrm{O}\right)$ compared with low PEEP $\left(3 \mathrm{~cm} \mathrm{H}_{2} \mathrm{O}\right)$ with the same peak pressure. Sandhar et al (23) subjected surfactantdepleted rabbits to mechanical ventilation with a peak airway pressure of about $30 \mathrm{~cm} \mathrm{H}_{2} \mathrm{O}$ and used different inspiratory:expiratory ratios to achieve the same mean airway pressure in the presence of both high and low PEEP. In one group of animals, they set the PEEP above the measured inflection point (around $14 \mathrm{~cm} \mathrm{H}_{2} \mathrm{O}$ ) and compared this with a group with a PEEP of $3 \mathrm{~cm} \mathrm{H}_{2} \mathrm{O}$. Oxygenation was higher in the high PEEP group, and histological examination of the lungs revealed significantly less hyaline membrane formation in the high PEEP group. In a rat model, Muscedere and colleagues (24) ventilated isolated, nonperfused, lavaged rat lungs with tidal volumes between 5 and $6 \mathrm{~mL} / \mathrm{kg}$ at different PEEP levels (below and above inflection point). The measured inflection point was around $15 \mathrm{~cm} \mathrm{H}_{2} \mathrm{O}$. One group of lungs was ventilated with no PEEP, another with PEEP below the inflection point $\left(4 \mathrm{~cm} \mathrm{H}_{2} \mathrm{O}\right)$ and another group with PEEP above the inflection point. Those lungs ventilated with 

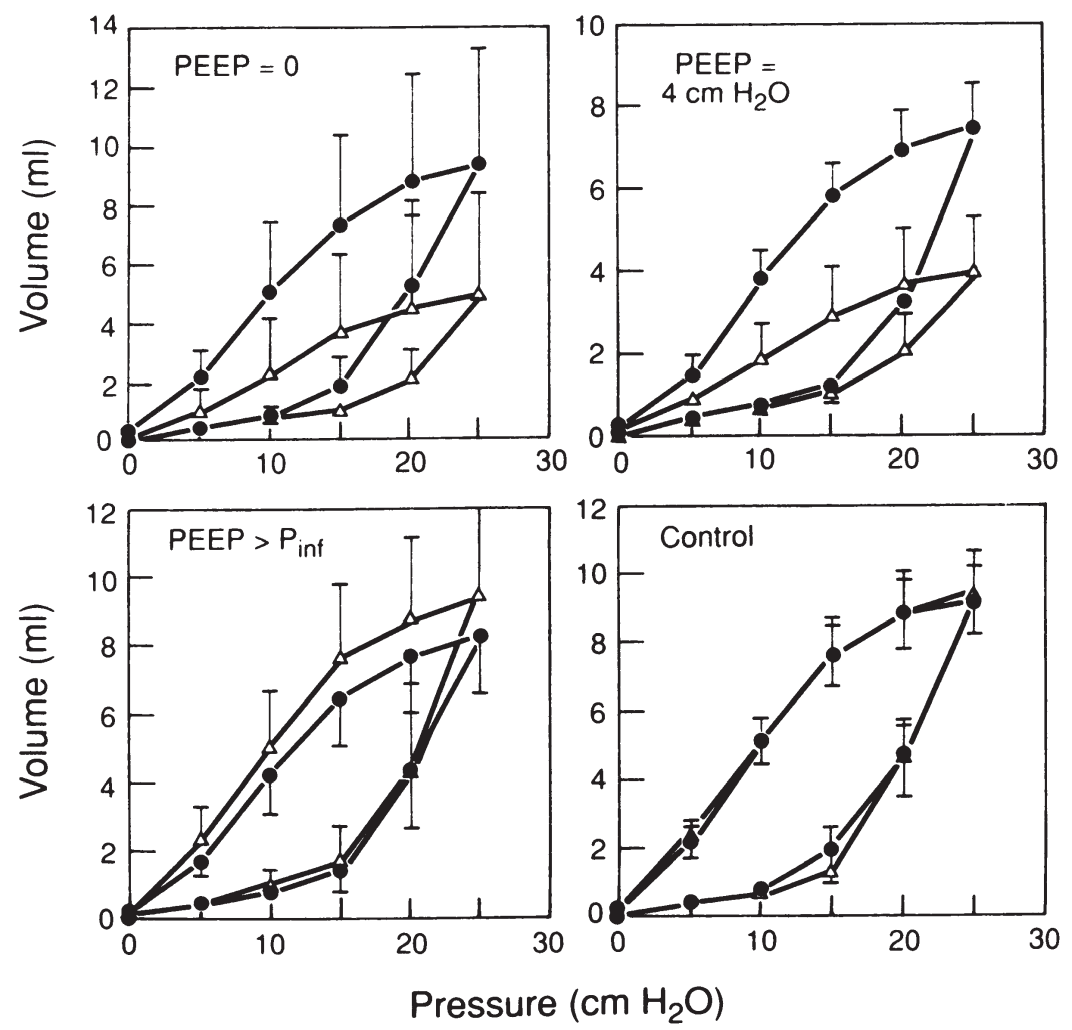

Figure 4) Composite pressure-volume curves before $(\bullet)$ and after $(\Delta)$ ventilation with different levels of peak end-expiratory pressure $(P E E P)$. Reproduced with permission from reference 24

no PEEP or PEEP below the inflection point had a marked decrease in compliance, whereas those ventilated above the inflection point had a significant increase in compliance (Figure 4). Histological examination of the lungs revealed that only the no PEEP and the PEEP below the inflection point groups had severe hyaline membrane formation.

Theoretically, during high frequency ventilation, the alveolar pressure swings should be less than conventional mechanical ventilation because of the relatively small tidal volumes used, thus minimizing the risk of barotrauma. Kolton et al (25) showed that high frequency ventilation produced better gas exchange and a lower incidence of hyaline membranes than did conventional mechanical ventilation only when high frequency ventilation was applied at a mean pressure above the opening pressure. From these reports, it appears that the development of hyaline membranes is associated with the repeated opening and closing of alveolar units and that maintenance of an end-expiratory lung volume at or above the inflection point is more important than other factors in minimizing lung damage (26-28).

\section{PEEP AND THE CLINICAL APPROACH IN ARDS}

It is unlikely that PEEP truly reverses any of the underlying pulmonary derangements once ARDS is established. As described above, independently of the clinical condition as- sociated with the development of acute lung injury, the mode of ventilation may alter the further development of lung injury. A ventilatory mode that fails to prevent partial or complete end-expiratory collapse may worsen lung damage.

Sjöstrand's group (29), using an animal model of acute lung injury induced by surfactant depletion, applied five established ventilatory modes, adjusting either volume or pressure to keep PEEP at about $16 \mathrm{~cm} \mathrm{H}_{2} \mathrm{O}$ and $\mathrm{PaCO}_{2}$ constant. They found that to open collapsed areas of the lung ventilated in their control mode, a pressure amplitude of $40 \mathrm{~cm} \mathrm{H}_{2} \mathrm{O}$ (peak pressure minus PEEP) had to be applied for 5 to 10 mins, and that after the lungs were opened, they could be adequately ventilated with pressure amplitudes of only about $20 \mathrm{~cm} \mathrm{H}_{2} \mathrm{O}$ (peak pressure of $35 \mathrm{~cm} \mathrm{H}_{2} \mathrm{O}$ ). Therefore, in order to prevent lung damage due to high shear forces between open and closed lung units, only ventilation modes that result in the smallest possible pressure amplitude should be used $(30,31)$. In other words, open up the whole lung and keep it totally open (30).

To date, no controlled outcome studies have been published demonstrating the best method of choosing the level of PEEP. PEEP is usually titrated using some index of oxygenation as an end-point. Within this global approach numerous methods have been described. Although the optimal method of applying PEEP is still quite controversial, simply using 


\section{TABLE 1}

\section{Approaches used to achieve the optimum level of PEEP}

\begin{tabular}{lccc}
\hline Investigators (reference) & Date & End-points & Terminology \\
\hline Suter et al (7) & 1975 & Maximum compliance & Optimal PEEP \\
Kirby et al (32) & 1975 & Reduction of shunt to 15\% & Super-PEEP \\
Demers et al (33) & 1977 & Highest $\mathrm{SvO}_{2}$ & Best PEEP \\
Walkinshaw et al (34) & 1980 & Maximal oxygen consumption & Preferred PEEP \\
Carroll et al (36) & 1988 & $\mathrm{PaO}_{2} \geq 60$ with $\mathrm{FiO}_{2}<0.6$ & Minimal PEEP \\
\hline
\end{tabular}

$\mathrm{FiO}_{2}$ Fraction of inspired oxygen; PEEP Peak end-expiratory pressure

increased $\mathrm{PaO}_{2}$ as the end-point is inappropriate because PEEP can have dramatic effects on other variables that affect tissue oxygenation. Investigators have suggested titrating the level of PEEP until oxygen delivery and compliance are maximized (7), intrapulmonary shunt is reduced to $15 \%$ (32), mixed venous oxygen saturation is increased (33), oxygen consumption is maximized (34) or adequate oxygenation is achieved with the lowest nontoxic fraction of inspired oxygen $\left(\mathrm{FiO}_{2}\right)$ (35) (Table 1). In practice, PEEP has been used in the way advocated by Carroll et al (36), that is, using the lowest level of PEEP that maintains an adequate $\mathrm{PaO}_{2}$ on an $\mathrm{FiO}_{2}$ less than $60 \%$ with minimal hemodynamic consequences.

Benito and Lemaire (37) analyzed the pressure-volume curves in patients with ARDS at three levels of PEEP $(0,10$ and $20 \mathrm{~cm} \mathrm{H}_{2} \mathrm{O}$ ). Only the application of $20 \mathrm{~cm} \mathrm{H}_{2} \mathrm{O}$ was able to suppress the inflection point of the ascending limb, to reduce hysteresis and to shift the pressure-volume trace upwards and to the left. Gattinoni et al (38) performed transverse computed tomography scans in supine ARDS patients and analyzed the data obtained from basal regions of the lung. The height of each lung was measured from its lowest (posterior) to its highest (anterior) point, and the lung was divided into 10 equal horizontal slices. Each of these sections was analyzed to determine its gas and tissue content, and the slices were compared to study the impact of PEEP. Gattinoni's group hypothesized that it is the pressure within the lower sections of the lung that mechanical ventilation must offset if the alveoli are to reopen. They confirmed that for recruitment to take place, PEEP levels must equal the superimposed hydrostatic pressure. However, it is possible that if sufficient PEEP is administered to inflate the most dependent regions, the normally aerated regions (nondenpendent regions) will be markedly overdistended.

\section{EFFECT OF PEEP ON OUTCOME FROM ARDS}

Treatment of ARDS with PEEP has been shown to improve oxygenation, but there are very few controlled studies of the effects of PEEP on ARDS outcome (31). There are no prospective studies of how or when it should be used. Support for the use of PEEP comes from historical comparisons of survival before and after the introduction of PEEP. Early application of PEEP appears to alter the degree of pulmonary deterioration, but does not prevent its occurrence. One well controlled study by Pepe et al (39) examining the prophylactic use of PEEP showed that there was no clinical utility to this approach. ARDS developed in $25 \%$ of patients with early PEEP and in $27 \%$ of patients in the control group. However, the absence of benefits observed by Pepe et al (39) could be misleading to the practicing intensivist. First, in their study, the level of PEEP chosen was $8 \mathrm{~cm} \mathrm{H}_{2} \mathrm{O}$, below the inflection point as determined in most studies (between 12 and $16 \mathrm{~cm}$ $\mathrm{H}_{2} \mathrm{O}$ ). Second, the tidal volume used was $12 \mathrm{~mL} / \mathrm{kg}$, a relatively large tidal volume, which likely produced overdistension and possible lung injury. Third, PEEP was intermittently removed for 8 mins before blood samples were obtained. More recently, DiRusso et al (40) retrospectively reviewed their experience in 86 ARDS patients treated with PEEP greater than $15 \mathrm{~cm} \mathrm{H}_{2} \mathrm{O}$. Nineteen patients died early of severe head trauma and were excluded from the evaluation. Only $30 \%$ of the remaining 67 patients died, representing a mortality rate lower than those previously reported using more conventional ventilatory techniques.

Since the original paper by the Denver group (2), PEEP was quickly adopted as standard practice for the treatment of ARDS. Because of this intuitive benefit, no prospective randomized trial of PEEP has ever been carried out in established ARDS patients to evaluate its efficacy. Recently, Slutsky (27) suggested a randomized clinical trial comparing conventional mechanical ventilation with a strategy that includes continuous volume recruitment. The amount of experimental evidence suggests that the theoretical rationale is sound, the animal data convincing and the preliminary human data encouraging (27). A recent study by Amato and colleagues (41) used a ventilation strategy that avoided alveolar overdistension (by limiting airway pressures and tidal volumes) and minimized cyclic reopening of collapsed alveoli (by the use of PEEP above the inflection point). They found that this combined approach was associated with improved lung function in patients with ARDS, and increased the chances of early weaning and lung recovery. A continuation of this trial in more patients has recently demonstrated that this strategy was associated with decreased mortality compared with a conventionally treated group (personal communication). However, it is unclear from this trial whether the beneficial effects are due to either or both of decreased lung overdistension and the use of high PEEP.

ACKNOWLEDGEMENTS: Supported by Fondo de Investigacion Sanitaria of Spain \& Medical Research Council of Canada. 


\section{REFERENCES}

1. Barach AL, Martin J, Eckman M. Positive pressure respiration and its application to the treatment of acute pulmonary edema. Ann Intern Med 1938;12:754-95.

2. Ashbaugh DG, Bigelow DB, Petty TL, Levine BE. Acute respiratory distress in adults. Lancet 1967;ii:319-23.

3. Falke KJ, Pontoppidan H, Kumar A, Leith DE, Geffin B, Laver MB. Ventilation with end-expiratory pressure in acute lung disease. J Clin Invest 1972;51:2315-23.

4. Shapiro BA, Cane RD, Harrison RA. Positive end-expiratory pressure therapy in adults with special reference to acute lung injury: a review of the literature and suggested clinical correlations. Crit Care Med 1984;12:127-41.

5. Stoller JK. Respiratory effects of positive end-expiratory pressure. Respir Care 1988;33:454-63.

6. Hedenstierna G, Santesson J, Norlander O. Airway closure and distribution of inspired gas in the extremely obese, breathing spontaneously and during anesthesia with IPPV. Acta Anaesthesiol Scand 1976;20:334-40.

7. Suter PM, Fairley HB, Isenberg MD. Optimum end-expiratory airway pressure in patients with acute pulmonary failure. N Engl J Med 1975;292:284-9.

8. Kacmarek RM. Positive end-expiratory pressure. In: Pierson DJ, Kacmarek RM, eds. Fundamentals of Respiratory Care. New York: Churchill Livingstone Publishers, 1992:891-920.

9. Paré PD, Warrimer B, Baile EM, Hogg JC. Redistribution of pulmonary extravascular water with positive end-expiratory pressure in canine pulmonary edema. Am Rev Respir Dis 1983;127:590-3.

10. Dueck R, Wagner PD, West JB. Effects of positive end-expiratory pressure on gas exchange in dogs with normal and edematous lungs. Anesthesiology 1977;47:359-66.

11. Dantzker DR, Lynch JP, Weg JG. Depression of cardiac output is a mechanism of shunt reduction in the therapy of acute respiratory failure. Chest 1980;77:636-42.

12. Manzano JL, Blazquez MA, Villar J, Villalobos J, Manzano JJ. Aplicacion de altos niveles de PEEP durante la ventilacion controlada. Med Intensiva 1981;5:10-7.

13. Qvist J, Pontoppidan H, Wilson RS, Lowenstein E, Laver MB. Hemodynamic responses to mechanical ventilation with PEEP. Anesthesiology 1975;42:45-55.

14. Fessler HE, Brower RG, Shapiro EP, Permutt S. Effects of positive end-expiratory pressure and body position on pressure in the thoracic great veins. Am Rev Respir Dis 1993;148:1657-64.

15. Pierson DJ. Alveolar rupture during mechanical ventilation: role of PEEP, peak airway pressure and distending volume. Respir Care 1988;33:472-86.

16. Webb HH, Tierney DF. Experimental pulmonary edema due to intermittent positive pressure ventilation with high inflation pressures. Protection by positive end-expiratory pressure. Am Rev Respir Dis 1974; 110:556-65.

17. Dreyfuss D, Soler P, Basset G, Saumon G. High inflation pressure pulmonary edema. Respective effects of high airway pressure, high tidal volume, and positive end-expiratory pressure. Am Rev Respir Dis 1988;137:1159-64

18. Cook CD, Mead J, Schreiner GL, Frank NR, Craig JM. Pulmonary mechanics during induced pulmonary edema in anesthetized dogs. J Appl Physiol 1959;14:177-86.

19. Slutsky AS, Scharf SM, Brown R, Ingram RH. The effect of oleic acid-induced pulmonary edema on pulmonary chest wall mechanics in dogs. Am Rev Respir Dis 1980;121:91-6.
20. Matamis D, Lemaire F, Harf A, Brun-Buisson, Ansquer JC, Atlan G. Total respiratory pressure-volume curves in the adult respiratory distress syndrome. Chest 1984;86:58-66.

21. Gattinoni L, Pesenti A. ARDS: the non-homogeneous lung; facts and hypothesis. Intensive Crit Care Digest 1987;6:1-4.

22. Corbridge TC, Wood LDH, Crawford GP, Chudoba MJ, Yanos J, Sznajder JI. Adverse effects of large tidal volume and low PEEP in canine acid aspiration. Am Rev Respir Dis 1990;142:311-5.

23. Sandhar BK, Niblett DJ, Argiras EP, Dunnill MS, Sykes MK. Effects of positive end-expiratory pressure on hyaline membrane formation in a rabbit model of the neonatal respiratory distress syndrome. Intensive Care Med 1988;14:538-46.

24. Muscedere JG, Mullen JBM, Gan K, Slutsky AS. Tidal volume at low airway pressures can augment lung injury. Am Rev Respir Dis 1994;149:1327-34.

25. Kolton M, Cattran CB, Kent G, Volgyesi G, Froese AB, Bryan AC. Oxygenation during high frequency ventilation compared with conventional mechanical ventilation in two models of lung injury. Anesth Analg 1982;61:323-32.

26. Mancebo J. PEEP, ARDS, and alveolar recruitment. Intensive Care Med 1992;18:383-5.

27. Slutsky AS. Barotrauma and alveolar recruitment. Intensive Care Med 1993;19:369-71.

28. Sykes MK. Does mechanical ventilation damage the lung? Acta Anaesthesiol Scand 1991;35(Suppl 95):35-9.

29. Lichtwarck-Aschoff M, Nielsen JB, Sjöstrand UH, Edgren EL. An experimental randomized study of five different ventilatory modes in a piglet model of severe respiratory distress. Intensive Care Med 1992;18:339-47.

30. Lachmann B. Open up the lung and keep the lung open. Intensive Care Med 1992;18:319-21.

31. Slutsky AS. Consensus Conference on mechanical ventilation - Part I. Intensive Care Med 1994;20:64-79.

32. Kirby RR, Downs JB, Civetta JM, et al. High level positive end-expiratory pressure (PEEP) in acute respiratory inssuficiency. Chest 1975;67:156-63.

33. Demers RR, Irwin RS, Bramen SS. Criteria for optimum PEEP. Respir Care 1977;22:596-601.

34. Walkinshaw M, Shoemaker WC. Use of volume loading to obtain preferred levels of PEEP. Crit Care Med 1980;8:81-6.

35. Weisman IM, Rinaldo JE, Rogers RM. Positive end-expiratory pressure in adult respiratory failure. N Engl J Med 1982;307:1381-4.

36. Carroll GC, Tuman KJ, Braverman B, et al. Minimal positive endexpiratory pressure (PEEP) may be "best PEEP". Chest 1988;93:1020-5.

37. Benito S, Lemaire F. Pulmonary pressure-volume relationship in acute respiratory distress syndrome in adults: role of positive end-expiratory pressure. J Crit Care 1990;5:27-34.

38. Gattinoni L, D'Andrea L, Pelosi P, Vitale G, Pesenti A, Fumagalli R. Regional effects and mechanism of positive end-expiratory pressure in early adult respiratory distress syndrome. JAMA 1993;269:2122-7.

39. Pepe PE, Hudson LD, Carrico CJ. Early application of positive end-expiratory pressure in patients at risk for the adult respiratory distress syndrome. N Engl J Med 1984;311:281-6.

40. DiRusso SM, Nelson LD, Safcsak K, Miller RS. Survival in patients with severe adult respiratory distress syndrome treated with high level positive end-expiratory pressure. Crit Care Med 1995;23:1485-96.

41. Amato MBP, Barbas CSV, Medeiros DM, et al. Beneficial effects of the open lung approach with low distending pressures in acute respiratory distress syndrome. Am J Respir Crit Care Med 1995; $152: 1835-46$ 


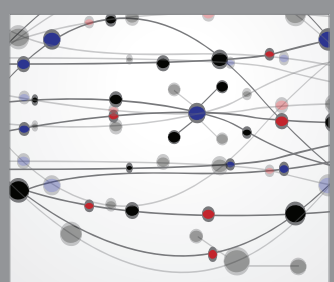

The Scientific World Journal
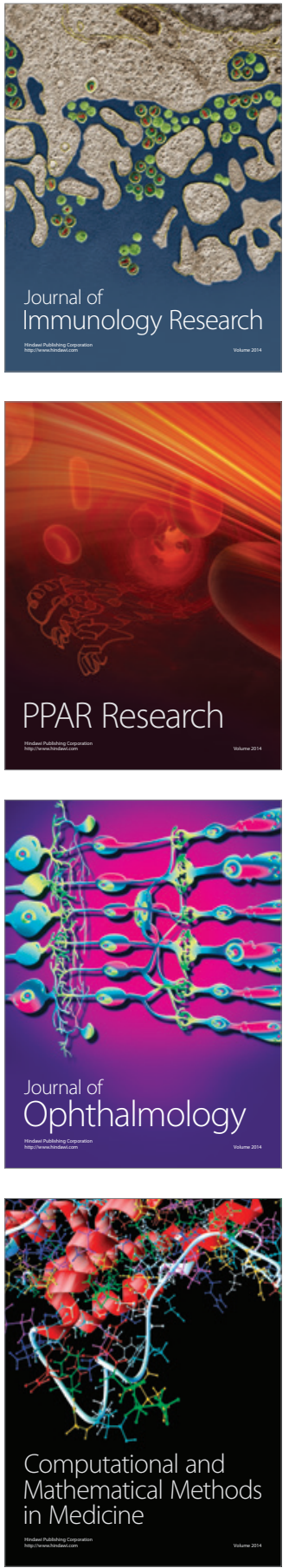

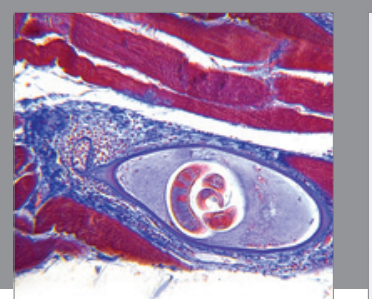

Gastroenterology Research and Practice

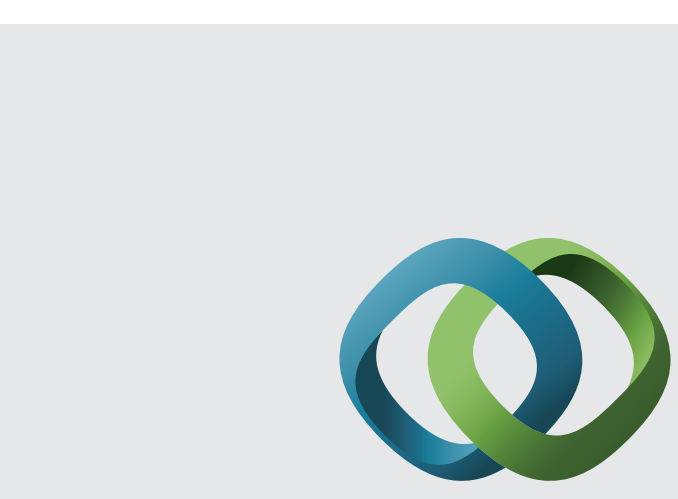

\section{Hindawi}

Submit your manuscripts at

http://www.hindawi.com
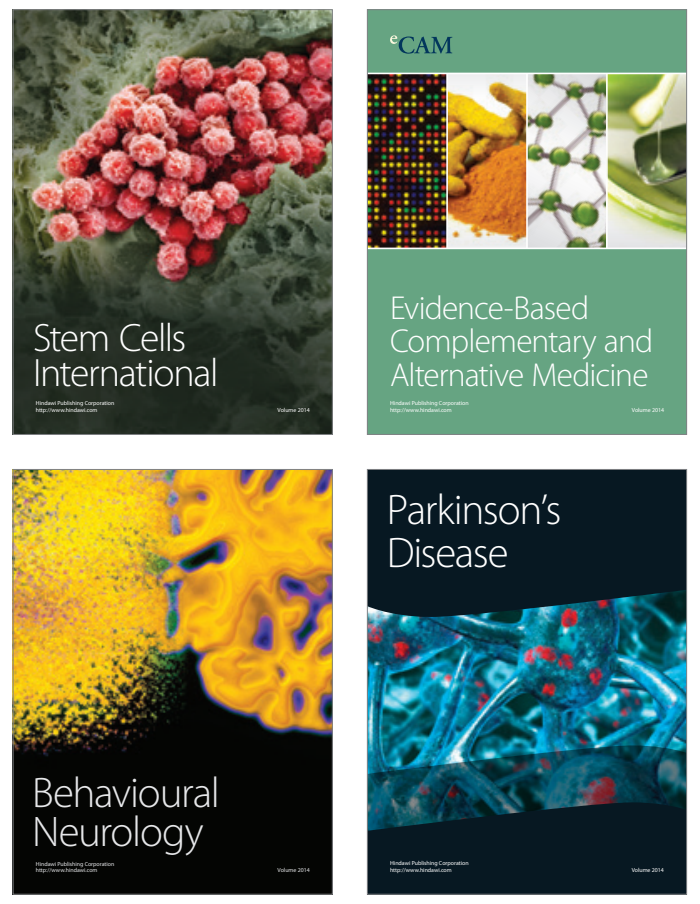
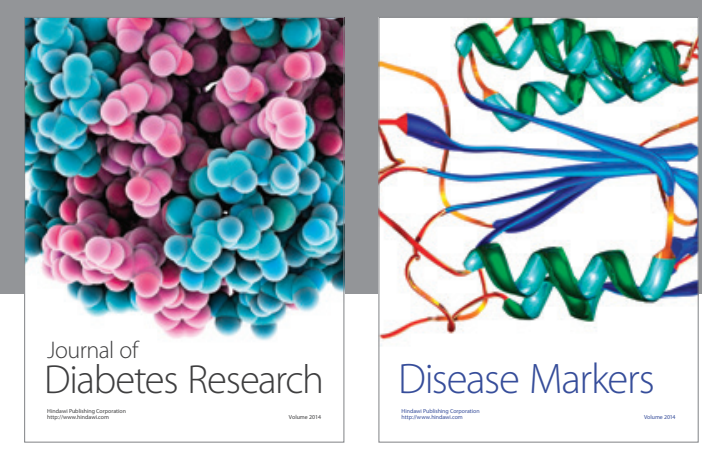

Disease Markers
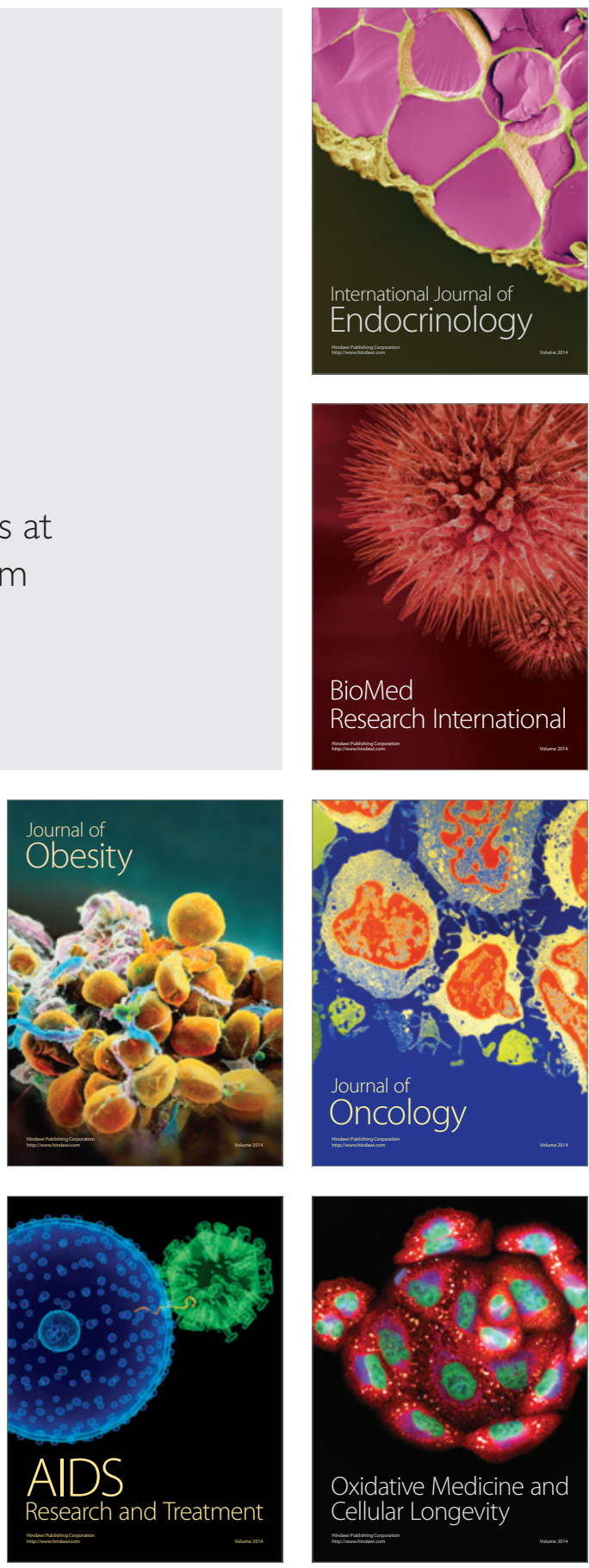